\title{
Implementasi Sapa Pagi dalam Pembinaan Etika Sosial Siswa SDN 52 Kota Bengkulu
}

\author{
Dilla Dwi Udiyana \\ Universitas Bengkulu \\ dilladwiudiyana0@gmail.com
}

Puspa Djuwita

Universitas Bengkulu

puspadjuwita58@gmail.com

\section{Pebrian Tarmizi}

Universitas Bengkulu

pebriantarmizi@yahoo.com

\begin{abstract}
This study aims to describe the implementation of morning greetings in the development to sosial ethics on cultural behavior $5 \mathrm{~S}$ (smile, greetin, greeting, polite, and courteous). The type of research used is descriptive quantitative research with descriptive method and percentage technique. The subjects of the study were VB students of 26 student.The research instrument is qualitative research that is self researcher, assisted by observation and interview guides plus quesionnaire sheect. Technique analysis of observation data and interview in narration while quesionanaire data(tecnique ercentage). From the result of research with the detail of the research that carry out the $5 \mathrm{~S}$ culture well as many as 18 student $(69,23 \%)$, able to undestand the implementation of sapa thismorning to prove the existence of the relationship of the morning greeting and behavior of the student, as many as 24 student(92,30\%)23 students $(96,15 \%)$ were able to have greeting attitude,as many as 23 student $(88,46 \%) 23$ students $(88,46 \%)$ able to have polite attitude. So the cunclusion of this study is that it can be said that the students of VB class have been implementing culture $5 \mathrm{~S}$ well.
\end{abstract}

Keywords: Social Ethisc,Culture 5S (Smile, Greet, Regards,Polite,Good) .

\begin{abstract}
Abstrak
Penelitian ini bertujuan untuk mendeskripsikan implementasi salam pagi dalam pengembangan etika sosial pada perilaku budaya $5 \mathrm{~S}$ (senyum, salam, salam, sopan, dan santun). Jenis penelitian yang digunakan adalah penelitian kuantitatif deskriptif dengan metode deskriptif dan teknik persentase. Subjek penelitian adalah siswa VB dari 26 siswa. Instrumen penelitian adalah penelitian kualitatif yaitu peneliti mandiri, dibantu oleh panduan observasi dan wawancara plus kuesioner quesionnaire sheect. Teknik analisis data observasi dan wawancara dalam narasi sedangkan data quesionanaire (tecnique ercentage). Dari hasil penelitian dengan detail penelitian yang melaksanakan budaya $5 \mathrm{~S}$ dengan baik sebanyak 18 siswa $(69,23 \%)$, mampu mengesampingkan
\end{abstract}


penerapan sapa pagi ini untuk membuktikan keberadaan hubungan salam pagi dan perilaku siswa, sebanyak 24 siswa (92,30\%) 23 siswa (96,15\%) mampu bersikap salam, sebanyak 23 siswa (88,46\%) 23 siswa $(88,46 \%)$ mampu bersikap sopan. Jadi kesimpulan dari penelitian ini adalah dapat dikatakan bahwa siswa kelas VB telah menerapkan budaya $5 \mathrm{~S}$ dengan baik.

Kata kunci: Etis Sosial, Budaya 5S (Senyum, Sapa, Salam, Sopan, Santun)

\section{Pendahuluan}

Pendidikan etika sebagai salah satu komponen dari Pkn, untuk menanamkan etika maka sekolah harus menanamkan sikap sopan santun yang baik pada siswa ketika akan memulai kegiatan dan mengakhiri kegiatan di sekolah. Penerapan etika tidak dapat dilakukan dengan hanya sekedar mentransfer ilmu pengetahuan atau melatih pemahaman konsep-konsep ilmu pengetahuan.

Salah satu contoh mendidik etika dapat dilakukan melalui budaya senyum, sapa, salam, sopan, dan santun (budaya 5S). Pembiasaan ini dijadikan sebagai ciri khusus seseorang atau suatu kumunitas, atau suatu komunitas lingkungan sekolah, atau lingkungan sekolah tertentu menjadi pembeda antara orang satu dengan yang lainnya, komunitas satu dengan komunitas lainnya, lingkungan satu dengan lingkungan lainnya, atau suatu sekolah satu dengan sekolah lainnya.

Dalam membentuk etika siswa menjadi manusia yang santun dapat dilakukan dengan budaya $5 \mathrm{~S}$ sehingga dimanfaatkan etika itu dalam menyongsong kehidupan yang akan datang. Dengan terbentuknya masyarakat atau individu yang memiliki etika seperti ini kita akan mampu menghasilkan generasi emas di kemudian hari yaitu generasi yang mampu memahami yang terimplementasi dalam perilaku saat dia berhubungan dengan temannya dan sesama manusia atau dalam kehidupan berbangsa dan bernegara.

Budaya 5S sudah terbiasa disebut dengan sapa pagi. Budaya 5S digunakan untuk menanamkan budaya yang baik sebelum memulai aktifitas. Budaya 5S merupakan suatu anjuran yang dilakukan oleh seseorang ketika sedang berkomunikasi dan bersosialisasi kepada orang lain. Karena kegiatan pagi hari sudah memulainya dengan kegiatan yang baik-baik dapat membuat kegiatan yang kita lakukan menjadi lebih berkah.

Seiring dengan perkembangan jaman dan modernisasi budaya 5S, maka orang mulai acuh dan meninggalkan budaya ketimuran tersebut. Melihat kenyataan tersebut, didapatkan beberapa siswa yang telah menjadi dampaknya modernisasi tersebut. Mereka sudah mulai tampak individu (memikirkan diri sendiri) sehingga kurang peduli kepada orang lain. Etika sosial dalam hal sopan santun mulai hilang dimana anak-anak sekarang kurang bisa menempatkan diri kepada siapa mereka bergaul dan bagaimana sikapnya kepada orang yang lebih tua termasuk kepada gurunya.

Melalui budaya $5 \mathrm{~S}$, diharapkan internalisasi pembentukan etika peserta didik mampu memahami nilai-nilai perilaku manusia yang berhubungan dengan Tuhan Yang Maha Esa, diri sendiri, sesama manusia, lingkungan dan kebangsaan. Kemudian nilai-nilai tersebut dapat terwujud dalam pikiran, sikap perasaan, perkataan, dan perbuatan berdasarkan norma-norma agama, hukum, tata krama, budaya, dan adat istiadat. 
Pendidikan dalam bentuk pengembangan etika melalui pembiasaan di Sekolah perlu diterapkan guna membentuk karakter luhur dari peserta didik. Pembiasaan ini dapat dilakukan melalui budaya 5S. Sebagaimana pendapat Lickona, (2016: 82) bahwa "pendidikan karakter yang baik perlu menekankan pada pembinaan perilaku secara berkelanjutan mulai dari proses knowing (pengetahuan moral), moral feeling (sikap moral), dan moral action (perilaku moral) dari pendidikan karakter". Budaya 5S dilaksanakan sebagai moral action (perilaku moral) dari pendidikan karakter sebagai upaya pembentukan akhlak.

\section{Metode}

Dalam penelitian ini digunakan jenis deskriptif kuantitatif dengan metode deskriptif dan teknik persentase. Lebih lanjut Sugiyono (2015: 51), "menjelaskan bahwa dalam penelitian deskriptif dengan pendekatan kuantitatif memerlukan alat berupa statistika deskriptif seperti teknik persen, mean, simpangan baku, korelasi, dan lainlain." Pada penelitian ini peneliti menggunakan teknik persen.

Bentuk analisisnya dilakukankan secara kuantitatif dan kualitatif. Analisis data secara kuantitatif menggunakan perhitungan statistik deskriptif (mean, variasi, dan lain-lain), sedangkan untuk analisis kualitatif mendeskripsikan hasil narasi dan pemaknaan dalam kegiatan sapa pagi.

Penelitian deskriptif kuantitatif dengan teknik persentase di sini bermaksud untuk mendeskripsikan hasil pengolahan data yang diperoleh berdasarkan persentase pada kegiatan sapa pagi dalam pembiasaan etika sosial di Bengkulu. Metode deskriptif kuantitatif dengan teknik persentase dalam penelitian ini untuk mendeskripsikan kegiatan sapa pagi dalam pembiasaan etika sosial.

Populasi dalam penelitian ini adalah seluruh siswa SDN 52 kota Bengkulu yang berjumlah 564 siswa. Sampel yang diperoleh yaitu kelas VB SDN 52 Kota Bengkulu yang berjumlah 26 siswa.

Instrumen yang digunakan oleh peneliti dapat membantu dan memudahkan dalam mengumpulkan data. Instrumen yang digunakan oleh peneliti adalah berupa lembar observasi dan lembar kuesioner. Lembar observasi yang digunakan ini untuk melihat kegiatan sapa pagi yang dilakukan siswa sehari-hari. Lembar kuesioner yang digunakan dalam mengetahui apakah siswa sudah memahami tentang kegiatan sapa pagi pada penilitian ini yaitu berbentuk soal pernyataan berjumlah 40 soal dengan cara menceklis jawaban yang dianggap benar.

Dalam penelitian ini terdapat dua teknik analisis data, yaitu analisis data dalam penelitian kualitatif dan kuantitatif. Penelitian kualitatif menggunakan analisis data dilapangan model Miles dan Huberman. Kemudian penelitian kuantitatif dalam analisis data meliputi analisis statistik deskriptif. Dalam penelitian kualitatif analisis data meliputi data reduction, data display, dan conclusion drawing/verification. Sedangkan penelitian kuantitatif Dalam penelitian ini analisis data yang digunakan meliputi uji prasyarat, statistik analisis persentase. Uji prasyarat meliputi Uji normalitas dengan menggunakan rumus chi-kuadrat.

\section{Hasil}

Dari hasil pengamatan umumnya siswa sudah mampu mengimplementasikan kegiatan sapa pagi saat dilapangan,dapat dilihat dari 26 siswa terdapat 24 siswa melakukan kegiatan tersenyum dengan persentase sebesar 92,30\%, siswa yang melakukan kegiatan menyapa sebanayak 23 siswa dengan persentase $88,46 \%$, 
sebanyak 25 siswa dengan persentase $96,15 \%$ melakukan kegiatan bersalaman, sebanyak 23 siswa dengan persentase $88,46 \%$ memiliki sikap sopan dan santun selama berada di lingkungan sekolah.

Setelah melakukan pengamatan dilanjutkan dengan mengisi lembar kuesioner (pernyataan) ini bertujuan untuk mengetahui apakah siswa sudah memahami kegiatan sapa pagi yang dilakukan setiap hari yang terdiri dari 40 pernyataan kepada 26 siawa kelas VB SDN 52 kota Bengkulu. Perhitungan uji-t dilakukan dan perhitungan uji normalitas. Pengujian normalitas bertujuan untuk mengetahui apakah kelas sampel pada penelitian ini berdistribusi normal atau tidak. Hasil dari perhitungan uji normalitas pada kelas VB SDN 52 Kota Bengkulu sebagai kelas sampel menunjukkan bahwa nilai $x^{2}$ hitung sebesar 8,56. Nilai $x^{2}$ tabel pada taraf signifikan 5\% sebesar 11,07. Artinya $x^{2}$ hitung $<x^{2}$ tabel. Hasil ini memberikan indikasi bahwa kelas sampel berdistribusi normal.

Berikut ini rekapitulasi hasil analisis deskriptif terhadap kemampuan siswa dalam menerapkan sapa pagi di kelas VB Sekolah Dasar Negeri 52 Kota Bengkulu. Dapat dimaknai bahwa penerapan budaya $5 \mathrm{~S}$ berdasarkan hasil perhitungan dan pengamatan dapat dilakukan analisis yang dilakukan sebagai berikut tentang sapa pagi dapat dilihat pada tabel 4.3 sebagai berikut.

Tabel 1. Hasil Rekapitulasi Analisis Deskriptif terhadap Penghitungan Persentasi Implementasi Sapa Pagi di Kelas VB Sekolah Dasar Negeri 52 Kota Bengkulu

\begin{tabular}{cccc}
\hline Jumlah Siswa & $\begin{array}{c}\text { Kategori Hasil } \\
\text { Analisis }\end{array}$ & $\begin{array}{c}\text { Interval Tingkat } \\
\text { Penguasaan }\end{array}$ & Persentase \\
\hline $\mathbf{8}$ & Sangat Baik & $109-132$ & $30,57 \%$ \\
$\mathbf{1 0}$ & Baik & $84-108$ & $38,46 \%$ \\
$\mathbf{5}$ & Cukup & $58-83$ & $19,23 \%$ \\
$\mathbf{3}$ & Kurang & $33-57$ & $11,53 \%$ \\
$\mathbf{2 6}$ & - & $\mathbf{1 0 0}$ & $\mathbf{1 0 0 \%}$ \\
\hline \multicolumn{4}{r}{ (Sumber: Hasil Penelitian 2018, Lampiran 14 Halaman 87) }
\end{tabular}

Berdasarkan hasil rekapitulasi analisis deskriptif terhadap Penghitungan Persentase Implementasi Sapa Pagi di Kelas V Sekolah Dasar Negeri 52 Kota Bengkulu di atas, terdapat 8 siswa (30,57\%) mendapatkan nilai dengan kategori sangat baik pada interval tingkat penguasaan yaitu 109-132, kemudian terdapat 10 siswa $(38,46 \%)$ mendapatkan nilai dengan kategori baik pada interval tingkat penguasaan 84-108, selanjutnya terdapat 5 siswa (19,23\%) mendapatkan nilai dengan kategori cukup pada interval tingkat penguasaan yaitu 58-83 dan terakhir terdapat 3 siswa (11,53\%) mendapatkan nilai dengan kategori kurang pada interval tingkat penguasaan yaitu 33-57. Dari hasil rekapitulasi di atas, peneliti melihat bahwa masih terdapat siswa yang sudah baik untuk menerapkan budaya $5 \mathrm{~S}$ dangan hasil yang baik dalam melaksanakan kegiatan sapa pagi ini setiap hari.

Siswa dikatakan mampu menerapkan budaya $5 \mathrm{~S}$ apabila mendapatkan nilai A dengan interval tingkat penguasaan 109-132 dan mendapatkan nilai B dengan interval tingkat penguasaan 84-108. Kemudian siswa dikatakan tidak mampu menerapkan budaya $5 \mathrm{~S}$ apabila mendapatkan nilai $\mathrm{C}$ dengan interval tingkat pengusaan 58-83 dan mendapatkan nilai D dengan interval tingkat pengusaan 3357. Dari perhitungan ini siswa yang betul-betul melaksanakannya sebanyakBerdasarkan data di atas, dapat dijelaskan bahwa siswa yang sudah terlihat dan tidak terlihat dalam implementasi sapa pagi adalah: 
Tabel 2. Rekapitulasi Siswa yang Mampu dan Tidak Mampu dalam Penghitungan Persentase Implementasi Sapa Pagi di Kelas VB Sekolah Dasar Negeri 52 Kota Bengkulu

\begin{tabular}{cccc}
\hline No & Kriteria & Jumlah Siswa & Persentase \\
\hline $\mathbf{1}$ & Mampu & 18 & $69,23 \%$ \\
$\mathbf{2}$ & Tidak utuh menjalankan & 8 & $30,57 \%$ \\
& Budaya 5S & & $\mathbf{2 6}$ \\
Jumlah & - & (Sumber: Hasil Penelitian 2018, Lampiran 16 Halaman 90)
\end{tabular}

Dari perhitungan ini siswa yang betul-betul melaksanakannya sebanyak 18 siswa yang sudah terlihat melaksanakan kegiatan sapa pagi dengan baik dan ada 8 siswa yang belum terlihat melaksanakan kegiatan sapa pagi karena kurangnya pemahaman siswa tentang pentingnya kegiatan sapa pagi ini dilakukan agar siswa memiliki sikap yang baik di dalam kehidupan kesehariannnya.

\section{Pembahasan}

Dalam penelitian ini kemampuan siswa dalam menerapkan sapa pagi di kelas VB Sekolah Dasar Negeri 52 Kota Bengkulu, dilihat dari penerapan siswa tentang budaya $5 \mathrm{~S}$ dan perilaku siswa ketika melakukan kegiatan sapa pagi dalam pembinaan etika sosial. Berdasarkan hasil penelitian siswa SDN 52 Kota Bengkulu baik dalam ketika melakukan kegiatan sapa pagi dilihat dari perilaku yang siswa, kegiatan belajar mengajar yang dilakukan juga sudah baik, kegiatan sapa pagi juga sudah baik dilaksanakan di sekolah tersebut.

Berdasarkan hasil yang telah diperoleh tersebut dikatakan dari 26 siswa dari perhitungan ini siswa yang betul-betul melaksanakannya sebanyak 18 siswa yang sudah terlihat melaksanakan kegiatan sapa pagi dengan baik dan ada 8 siswa yang belum terlihat melaksanakan kegiatan sapa pagi. 18 siswa $(69,23 \%)$ yang selalu melaksanakan kegiatan sapa pagi di SDN 52 kota Bengkulu dilihat dari tes pernyataan pada lembar kuesioner yang diberikan setelah melakukan observasi/pengamatan.

Bahwa dengan kegiatan sapa pagi merupakan hubungan sosial dan pada umumnya siswa sudah bisa melakukannya hanya beberapa siswa saja yang belum sesuai melakukannya sejalan dengan pendapat (Adisusilo, 2014: 54) yaitu etika yang menjadi pegangan hidup seseorang dalam bertingkah laku di dalam kehidupan yang sesuai dengan kode etik sebagai ilmu tentang baik dan buruk demi membentuk etika sosial yang baik dalam berperilaku.

Berdasarkan hasil observasi/pengamatan siswa dalam menerapkan kegiatan sapa pagi dalam pembinaan etika sosial ini sudah terlihat dari kegiatan budaya $5 \mathrm{~S}$ yaitu terdapat sebanyak 24 siswa $(92,30 \%)$ yang selalu tersenyum, sebanyak 23 siswa $(88,46 \%)$ yang selalu menyapa, sebanyak 25 siswa $(96,15 \%)$ yang selalu memberikan salam, sebanyak 23 siswa $(88,46 \%)$ yang melalu bersikap sopan, sebanyak 23 siswa $(88,46 \%)$ yang selalu bersikap santun.

Secara keseluruhan yang telah dibahas dari 26 siswa terdapat 18 siswa yang selalu menerapkan senyum, sapa, salam, sopan, dan santun dan hanya 8 siswa yang belum konsisten atau secara kontinue melaksanakan kegiatan Budaya 5S. Sejalan dengan pendapat Gunawan (2014: 18) yang mengatakan bahwa etika sosial merupakan hubungan manusia dengan manusia baik secara langsung maupun secara kelembagaan (keluarga, masyarakat dan negara) berfungsinya makna etika sosial dalam proses pendidikan. 
Setelah dilihat dalam keseharian siswa yang belum terlihat melaksanakan sapa pagi (Lampiran 17) karena orang tua tidak terbiasa melakukan kegiatan sapa pagi ini sehingga sebagian kecil yang belum mampu melaksanakan sapa pagi dengan baik juga harus di dukung oleh keluarga agar menjadikan siswa tersebut menjadi pribadi yang lebih baik. Jadi, hasil pengamatan siswa sudah terlihat memiliki perilaku yang baik dalam kesehariannya hanya beberapa siswa yang perlu bimbingan agar benarbenar menerapkannya secara baik, dari dapat disimpulkan bahwa siswa kelas VB sudah baik dalam pelaksanaan kegiatan sapa pagi.

\section{Simpulan}

Berdasarkan hasil penelitian dan pembahasan, maka dapat disimpulkan bahwa terdapat dampak implementasi sapa pagi dalam bidang etika dapat dilihat dari kegiatan sehari-hari siswa di Kelas V Sekolah Dasar Negeri 52 Kota Bengkulu. Siswa mampu menjawab lembar kuesioner (pernyatan) dengan jumlah siswa 18 siswa dengan persentase $69,23 \%$ yang sudah mampu melaksankan sapa pagi dengan konsisten dan hanya 8 siswa yang belum mampu melakukan sapa pagi dengan baik dengan persentase $30,57 \%$ dalam kemampuan siswa dalam menerapkan sapa pagi, dan melaksanakan kegiatan budaya $5 \mathrm{~S}$ membuktikan adanya hubungan implementasi sapa pagi dan perilaku siswa.Pembinaan etika sosial sudah mulai tampak dilakukan dari 26 siswa terdapat 24 siswa (92,30\%) mampu memiliki sikap senyum, sebanyak 23 siswa $(88,46 \%)$ mampu memiliki sikap sapa, sebanyak 25 siswa (96,15\%) mampu memiliki sikap salam, sebanyak 23 siswa $(88,46 \%)$ mampu memiliki sikap sopan, sebanyak 23 siswa $(88,46 \%)$ mampu memiliki sikap santun. Jadi, implementasi ini sudah berhasil dilakukan karena mampu memiliki perilaku yang baik dalam kesehariannya, dari dapat disimpulkan bahwa siswa kelas VB sudah baik dalam pelaksanaan kegiatan sapa pagi.

\section{Saran}

Berdasarkan hasil penelitian yang telah dilakukan, maka peneliti memberikan saran:

1. Sebagai masukan bagi kepala sekolah untuk dapat mengembangkan kebiasaan baik selalu kepada siswa agar semakin terbentuknya etika sosial yang mampu membuat prilaku siswa menjadi lebih baik.

2. Bagi guru agar dapat menggunakan kebiasaan hidup jujur kepada siswa dan selalu menyelesaikan perselisihan secara langsung agar siswa tidak memiliki rasa dendam kepada sesama sehingga didalam pembelajaran juga lebih menyenangkan dan menjadikan pembelajaran menjadi lebih efektif sehingga mampu meningkatkan hasil belajar.

3. Bagi siswa agar dapat menggunakan etika sosial sebagai acuan untuk berperilaku agar siswa memiliki sikap yang sesuai aturan yang berlaku didalam kesehariannya.

4. Bagi pembaca agar dapat meneruskan penelitian imlementasi sapa pagi ini dengan menggunakan pendekatan-pendekatan lainnya untuk melihat konsistennya etika sosial siswa dan pemahamannya tentang kegiatan sapa pagi.

\section{Referensi}

Alfonsus , S. 2008. Etiket Kiat Serasi Berelasi. Yogyakarta: Kanisius.

Arikunto, S. 2010. Prosedur Penelitian Suatu Pendekatan Praktik, Jakarta: PT. Rineka Cipta.

2013. Dasar-Dasar Evaluasi Pendidikan Edisi Kedua, Jakarta: Bumi Aksara. 
Aziz, M.2011. Hadits-Hadits Pilihan Untuk TK-SD-SMP, Jakarta: Sholahuddin Press.

Bertens, K. 2013. Etika. Yogyakarta: PT Kanisius.

Departemen Pendidikan Nasional. 2008. Kamus Besar Bahasa Indonesia. Jakarta: Balai Pustaka.

Gunawan, H. 2014. Pendidikan Karakter: Konsep dan Implementasi. Bandung: Alfabeta.

Hariyadi, H. 2009. Administrasi Perkantoran untuk Managemen \& Staf. Jakarta Selatan : Transmedia Pustaka.

Kementerian Pendidikan Nasional, Kebijakan Nasional Pembangunan Karakter Bangsa Tahun 2010-2025. Jakarta, Kementerian Pendidikan Nasional, 2013.

Kurniawan, S. 2016. Pendidikan Karakter: Konsepsi dan Implementasi secara Terpadu di Lingkungan Keluarga, Sekolah, Perguruan Tinggi \& Masyarakat. Yogyakarta: Ar-Ruzz Media.

Kamus Besar Bahasa Indonesia (KBBI), (online) Tersedia di https://kbbi.web.id/peduli.

Mustari, M. 2011. Nilai Karakter Refleksi untuk Pendidikan Karakter. Yogyakarta: Laksbang Pressindo.

Najieh, A. 1984. 323 Hadits dan Sya-ir untuk Bekal Da'wah. Jakarta: Pustaka Amani.

Lickona, T. 2016. Mendidik Untuk Membentuk Karakter: Bagaimana Sekolah Dapat Memberikan Pendidikan tentang Sikap Hormat dan Bertanggung Jawab. Jakarta: Bumi Aksara.

Salam, B. 1997. Etika Sosial Asas Moral dalam Kehidupan Manusia, Jakarta: Rineka Cipta.

Sukmadinata, Nana Syaodih. 2011. Metode Penelitian Pendidikan. Bandung: Remaja Rosdakarya

Sugiyono. 2015. Metode Penelitian Pendidikan, Pendekatan Kuantitatif, Kualitatif dan $R \& D$. Bandung: Penerbit Alfabeta.

2016. Metode Penelitian Pendidikan, Pendekatan Kuantitatif, Kualitatif dan $R \& D$. Bandung: Penerbit Alfabeta.

Hadi, S. 2013. Keajaiban Senyuman Menguak Rahasia di Balik Senyuman dan Tawa dalam Bisnis, Kesehatan, dan Penyembuhan. Yogyakarta. Gava Media.

Winarni, E., W. 2011. Penelitian Pendidikan. Bengkulu: Unit Penerbitan Fkip Unib.

Ya'kub, H. 1991. Etika Islam Pembinaan Akhlakul Karimah, Bandung: Diponegoro. 
E, A., D. 2016. Implementasi Pendidikan Karakter 5S (Senyum, Sapa, Sapa, Salam, Sopan, Santun) Di SMAN 3 Sidoarjo, Jurnal Inspirasi Manajemen Pendidikan, vol. 1, no. 1, Hal: 1-5

Widyanti, H. 2014.s Pembentukan Karakter Siswa Melalui Program Lima S (Senyum, Sapa, Sapa, Salam, Sopan, Santun) Di SMAN 1 Sidoarjo, Kajian Moral dan Kewarganegaraan, vol.3, no. 2, Hal: 784-798 